\title{
Faculty Development Needs as a Function of Status in the Academic Guild
}

\section{Sandra Powell Barber}

Henderson Community College

Faculty members today face a professional identity crisis. They belong to a relatively stable, permanent corps (Chait and Gueths, 1981). Insufficient attrition and increased retention of faculty in postsecondary institutions reduces mobility of faculty members (Chait and Gueths, 1981), and the higher salary provided by a potential employer may not offset the appreciable moving expenses when an opportunity does arise. The modal age of tenured faculty today is 36 to 45 ; by the year 2000 , the modal age will be 56 years. Colleges and universities presently have more associate and full professors than faculty at the junior level.

Limited prospects for long-term advancement discourage many faculty. The faculty member's responsibility for the "holy trinity" of teaching, research, and service outstrips the time available in a day. There remains little time for renewal. Some faculty members consider themselves an endangered species, struggling to keep abreast of the never-ending explosion of knowledge and to cope with rapid technological change.

Finally, faculty members claim that accountability replaces concern for quality in the learning process. Postsecondary institutions typically make it mandatory for faculty to participate in a performance evaluation process, but this type of evaluation remains summative in nature and does not provide guidance for faculty renewal. In contrast, analysis of faculty members' needs 
can become the basis for constructive faculty development programming.

As Bowen and Schuster (1986, p. 29) claim, "The faculties of America are a great national resource which have been subjected to deferred maintenance." Yet the continued growth and improvement of both the academy and the teaching-learning process remains dependent upon renewing and revitalizing the faculty. Clark $(1985$, p. 8) defines faculty development as a program of structured activities that promote self-renewal, personal and professional growth, teaching effectiveness, and life-long career development. Faculty development focusses on improving professional competence (Harrington, 1986). However, "professional competence" is not a static entity. At each stage of a faculty member's career, different needs become salient. This paper analyzes faculty careers in an attempt to uncover faculty members' needs related to the academic guild through which they ordinarily progress. I identify these needs and discuss their application in specific academic settings.

\section{PROFESSIONAL DEVELOPMENT STAGES}

The academy possesses its own guild system. Each rank within the guild has distinctive characteristics and areas of concern for professional development. While the salience of these concerns varies among individual faculty members, it is possible to construct a prototype or portrait for each position in the guild. This portrait or "faculty profile" provides clues to the professional development needs of the faculty at various stages in their careers (refer to the summary in Appendix).

The typical assistant professor spends his or her time working towards tenure. The emphasis in this rank centers on research productivity recorded in publications. The discipline serves as the professional reference group for the assistant professor (Freedman et al., 1979, p. 62). Developmentally, this junior faculty member values knowledge for knowledge's sake, looks upon education as pouring facts into empty vessels, and identifies students as empty vessels (Ralph, 1973). The assistant professor's outlook on the learning process lacks complexity and flexibility, and emphasizes competition among students.

The tenured associate professor seeks to balance professional and personal goals (McKeachie, 1983). This faculty member 
possesses the ability to work toward distant goals. He or she engages in avocational pursuits and community service activities (Freedman et al., 1979, p. 98). Developmentally, the associate professor views knowledge as complex, students as people acquiring facts, and education as the process of creating conditions for learning.

The full professor, the most senior member of the guild, spends his or her time polishing contributions to the academy. Senior faculty members vary in productivity. The emphasis at this guild level is on the faculty member's position as an expert, a mentor, and a member of multiple distant reference groups. A full professor's goals include preparation for career transition to administration or a new field, and retirement planning. Developmentally, the full professor refines knowledge with the realization that he or she knows so little of what can be known. For these individuals, education involves intellectual engagement and the ability to synthesize. Many full professors think students should discover "answers" for themselves. They view their role with students as one of guidance. In outlook, full professors convey the greatest tolerance, complexity and flexibility in the teaching-learning process. However, as noted in the introduction, many senior faculty members become disillusioned and feel stuck in their professional roles. Attention to faculty development needs at all levels can help faculty remain committed, active, and flexible throughout their professional careers.

\section{STAGE-RELATED FACULTY DEVELOPMENT NEEDS}

Occupants in each rank in the academic guild have characteristic faculty development needs corresponding to their professional concerns. Junior faculty members, including instructors and assistant professors, exhibit five types of needs. The opportunity to serve a professional apprenticeship fulfills the junior faculty member's need for guidance in the early stages of career development. As an apprentice, the junior faculty member follows a role model, a mentor from the senior ranks who guides him or her through the hurdles of tenure and promotion and listens to problems along the way. Professional involvement needs for junior faculty include participation in appropriate disciplinary associations, networking, continuing education, research, and publication. Instructionally-related needs involve 
learning varied teaching techniques, mastering the use of audiovisual aids, developing skill in course design, and understanding the teaching improvement process (Kerwin, 1985). Advising needs focus on techniques to use when advising students, instructional support for advising, and understanding student development models such as Chickering's "vectors." Service needs include identifying community concerns, selecting appropriate activities, and learning how to serve most effectively.

While rank determines a considerable proportion of a faculty member's needs, professional development needs can also vary according to the type of college or university setting in which the individual serves. For example, junior faculty members in a community college system need to (a) participate on committees at the college and system level, (b) engage in professional activities such as discipline and system-wide conferences, (c) develop student advisory expertise, and (d) expand knowledge of instructional techniques (Kerwin, Note 1). In contrast, junior faculty members in a research institution need programs to foster research productivity; like their counterparts in community colleges, they need to develop instructional techniques as well, particularly in areas such as teaching strategies, testing, and grading (Altman, Note 1).

Senior faculty include associate and full professors who manifest five types of faculty development needs. A mentorship meets their recognition need by allowing them to work with and guide junior faculty members, but this role requires training. Career assessment needs focus on development of new roles, retraining, consulting (internal and external in nature), and administrative service. Instructional renewal needs for senior faculty members can be met by training them to be teaching consultants. This role provides senior faculty members with the opportunity to share their expertise while refining their own teaching techniques. Within the renewal needs category, faculty members can engage in faculty exchange programs, sabbatical leaves, paid leaves, skill development programs, retirement planning, and academic elder statesperson roles related to teaching, research, and service. Renewal for senior faculty members often comes in the form of recognition for serving in the academy.

Renewal strategies appropriate for senior faculty members 
in a community college include independent study, sabbaticals, writing books, and participating in summer teaching fellowships to support course redesign and advanced study (Kerwin, Note 1). Within the regional university, senior faculty members can meet their career assessment needs through taking a leadership role. In a university setting, faculty members need to make every effort to stay current. They can also benefit from working in industry or business for a year and from active community service (Auer, Note 1).

New faculty members (at all ranks) possess three types of faculty development needs. They need orientation to the mission of the school; its procedures, policies, and benefits; the environment of the school and community; and the type of students they can expect in their classes. New faculty members need to understand the institutional hierarchy and the folkways among faculty, administrators, and students. The role expectation needs of a new faculty member include a definition of their responsibilities in regard to teaching, research, and service as well as an explanation of the evaluation process and the reward system in the institution.

Most new faculty members need basic information about their new college environment. Faculty members at a regional university need guidance from the department chair on syllabus construction, course content expectations, and the procedures and policies outlined in the faculty handbook (Auer, Note 1). In a private, four-year college, new faculty members need orientation to the special mission and purpose of the institution. This orientation might include workshops on role expectations, committee service, student culture, policies, and characteristics of the school (Clark, Note 1).

Regardless of institutional setting, faculty members share development needs based on their rank in the academic guild. New faculty members need orientation to the institution, its mission, and its procedures; junior faculty members need to serve as apprentices under senior mentors; and senior faculty members need renewal and revitalization.

\section{FACULTY DEVELOPMENT: A NEED FOR THE ACADEMY}

Faculty development emphasizes the renewal and revitalization of a natural resource imperiled: the American professoriate 
(Bowen \& Schuster, 1986). The primary purpose of faculty development is professional improvement (Harrington, 1986), but a well rounded faculty development program looks at the faculty member as a person and facilitates the individual's personal as well as professional growth at every stage in his or her career. Faculty development necessitates a coordinated effort by administrators and faculty members. Faculty members must commit themselves to lifelong learning, while administrators must provide the financial support, resources, and institutional encouragement for faculty renewal efforts.

Postsecondary institutions benefit from the dedication of people who serve on their faculties. These experts, representative of many disciplines, impart knowledge and ignite students' desire for continued learning. Faculty development programs help faculty members cope with the knowledge explosion, acquire new skills, and improve their effectiveness. Renewed and revitalized faculty members are excited about what they do and work to improve the teaching-learning process. The renewal gained through faculty development, then, benefits both the academy and its members.

\section{REFERENCES}

Bowen, H. R., and Schuster, J. H. (1983). American professors: A National resource imperiled. New York: Oxford University Press.

Chait, R. P., and Gueth, J. (1981). Proposing a framework for faculty development. Change, 13(4), 30-33.

Clark, R. S. (1985). A study of chief academic officers' role in faculty development in level II colleges of the Southern Association of Colleges and Schools. Unpublished doctoral dissertation, George Peabody College for Teachers of Vanderbilt University, Nashville.

Freedman, M., Brown, W., Ralph, N., Shukraft, R., Bloom, M., \& Sanford, N. (1979). Academic culture and faculty development. Berkeley, CA: Montaigne Press.

Harrington, C. Tracy (1986, June 24). Faculty development and faculty evaluation: Creating a symbiosis. Unpublished address, Statewide Conference on Faculty Development in Kentucky Higher Education, Louisville.

McKeachie, W. J. (1983). Faculty as a renewable resource. In R. G. Baldwin \& R. T. Blackburn (Eds.), College faculty: Versatile human resources in a period of constraint [Entire issue]. New Directions for Institutional Research, 10(4), 57-66. 
Ralph, N. (1973). Stages of faculty development. In M. Freedman (Ed.), Facilitating faculty development [Entire issue]. New Directions for Higher Education, 1(1), 61-68.

\section{NOTES}

1. Recommendations for individual college settings are based on interviews with the following people; Michael Kerwin, the Community College System/University of Kentucky; Tom Auer, Murray State University; Howard Altman, University of Louisville; and Robert Clark, Campbellsville College.

\section{APPENDIX \\ Faculty Profile}

\section{A. PROFILE BY RANK}

\section{Assistant Professor}

Working towards tenure

Emphasis-research productivity

Professional reference groupdiscipline

Developmental stage:

knowledge-absolute terms education-pouring facts into empty vessels students-empty vessels outlook-dogmatic, lack complexity, competitive

\section{Associate Professor}

Has achieved tenure

Seeks balance between professional, personal goals

Able to work towards more distant goals

Active in avocational pursuits, community service

Developmental state:

knowledge-more complex education-a process, create conditions for learning students-are people acquiring facts

outlook-less dogmatic, see causal relationships

\section{Full Professor}

Polishing contributions to academy; variance in productivity

Empahsis-position as expert, mentor; distant reference group

Goals-pursuits for career transition (administration, new career, retirement)

Developmental stage: knowledge-refining, realize how little they know education-engagement, ability to synthesize students-discover answers themselves; guide them outlook-flexible, tolerant, complex 
B. NEEDS RELATED TO

\section{ACADEMIC GUILD STATUS}

New Faculty, Part-time Faculty Needs

Orientation

mission of institution

procedures, policies, bene-

fits

environment (school, community)

type of student (cultures)

Communication

structural-hierarchy

folkways -faculty, student, administration

Role expectation

teaching-syllabus, texts, objectives

research

service

evaluation process

reward system

Junior Faculty Needs

Apprenticeship (tutelage, novitiate)

role model

tenure and promotion

listener

Professional involvement appropriate associations

level of involvement, networking

continuing edcuation

research, publication

career counseling

Instructional techniques

teaching modes

course designs

audiovisual aids

TIP-teaching improvement process

Advising

techniques

institutional support

vectors of student development

Service

types of service

community needs

techniques

\section{Senior Faculty Needs}

Mentorship

training, release time

listening, guiding junior faculty

Career assessment

new roles, retraining

consulting (internal and external)

administrative service

Instructional improvementTIP

Renewal

faculty exchange

sabbatical leaves

paid leaves

government service

study abroad

institute, industry, or business internship

Future planning avocational pursuits personal skills development retirement planning academic elder statesperson role in teaching, research, and service 